\title{
Potential of single and double-combined adsorbents in removing chromium from an industrial wastewater
}

\author{
S.F. Mousavi ${ }^{1}$, R. Rostamian ${ }^{2}$ and A. Aghakhani ${ }^{3}$ \\ Department of Civil Engineering, Semnan University, Semnan 35131-19111, Iran. \\ ${ }^{2}$ Department of Water Engineering, Isfahan University of Technology, Isfahan 84156-83111, Iran. \\ ${ }^{3}$ Department of Water Engineering, Isfahan University of Technology, Isfahan 84156-83111, Iran.
}

\begin{abstract}
Nowadays, there is much attention in using low-cost methods for removing heavy metals' pollution from wastewaters. In this research, the ability of different adsorbents including zeolite, peat, activated carbon, cationic resin and anionic resin (in single and double-combined forms) in decreasing $\mathrm{Cr}(\mathrm{III})$ and $\mathrm{Cr}(\mathrm{VI})$ concentration to below the legal limits from an industrial wastewater was investigated. The results showed that for single-adsorbent treatments, all adsorbents were more effective in reducing $\mathrm{Cr}(\mathrm{VI})$ concentration than $\mathrm{Cr}(\mathrm{III})$. The highest removal efficiency $(\mathrm{Er}=100 \%)$ was obtained by anionic resin. Presence of anionic resin in each double-adsorbent caused an improvement of chromium removal. Among the double-adsorbents treatments, combination of peat and activated carbon was the most proper treatment in removing chromium.
\end{abstract}

Keywords: Heavy metals; Chromium; Adsorbent

\section{Introduction}

Heavy metals (HMs) are among the most important environmental pollutants which are becoming a severe public health problem. One of the toxic HMs in the wastewaters is chromium. Chromium compounds occur mainly in the environment as trivalent, $\mathrm{Cr}(\mathrm{III})$, and hexavalent, $\mathrm{Cr}(\mathrm{VI})$ ions. $\mathrm{Cr}(\mathrm{VI})$ is a highly toxic metal. $\mathrm{Cr}(\mathrm{III})$ is an essential element and is much less toxic than $\mathrm{Cr}(\mathrm{VI})$. Adsorption is one of the effective techniques for HMs removal from wastewaters. Application of different adsorbents such as zeolite, peat, activated carbon, anionic resin and cationic resin to remove HMs from the aqueous phase has been widely studied (Wu et al., 2008; Zeng et al., 2010; Ulmanu and Anger, 2008; Choi et al., 2009 Pehlivan and Cetin, 2009; Alguacil et al., 2004).

It is often necessary to remove chromium from wastewaters so that the effluent could be reused as irrigation water. The permissible limits of $\mathrm{Cr}(\mathrm{III})$ and $\mathrm{Cr}(\mathrm{VI})$ concentration for surface irrigation reuse of water is $2 \mathrm{mg} \mathrm{L}$ and $1 \mathrm{mg} \mathrm{L}^{-1}$, respectively (Environmental Protection Organization of Iran, 2000). The adsorption capacity of various adsorbents in removing HMs is different. Finding low-cost adsorbents with high adsorption capacity is the best method for alleviating the HMs pollution. For this reason, the objective of the present research was to study the ability of different adsorbents in single and double forms, to remove $\mathrm{Cr}(\mathrm{III})$ and $\mathrm{Cr}(\mathrm{VI})$ from an industrial wastewater.

\section{Materials and Methods}

Zeolite, peat, activated carbon, anionic resin and cationic resin were used as an adsorbent in the single and doubled combined. Table 1 shows the main treatments of this study. The amount of total adsorbent in each treatment was the same. Characteristics of each adsorbent are described as follows.

In this research, the industrial wastewater from one of the steel factories in the region was used as the aqueous solution for testing the efficiency of the above-mentioned adsorbents for removing chromium. Initial concentrations of total chromium and $\mathrm{Cr}(\mathrm{VI})$ were $60.2 \mathrm{mg} \mathrm{L}^{-1}$ and $45.15 \mathrm{mg}$ $\mathrm{L}^{-1}$, respectively. $\mathrm{pH}$ of the wastewater was 5.45. In this experiment, for each treatment, 1.0 gram of single or combined adsorbent was added to $50 \mathrm{ml}$ of the solution and the flasks were shaken thoroughly (at a speed of $180 \mathrm{rpm}$ ) in the laboratory temperature for $4 \mathrm{hr}$. For combination 
E3S Web of Conferences

Table 1- Single adsorbents and their combinations used in the experiment

\begin{tabular}{|c|c|c|c|c|c|c|c|c|}
\hline Specified letter & $\mathrm{S} 1$ & $\mathrm{~S} 2$ & S3 & S4 & S5 & D1 & $\mathrm{D} 2$ & D3 \\
\hline Adsorbent & $Z^{*}$ & $\mathrm{P}$ & $\mathrm{AC}$ & $\mathrm{AR}$ & $\mathrm{CR}$ & $\mathrm{Z}, \mathrm{P}$ & $\mathrm{Z}, \mathrm{AC}$ & $\mathrm{Z}, \mathrm{AR}$ \\
\hline Specified letter & D4 & D5 & D6 & D7 & D8 & D9 & $\mathrm{D} 10$ & \\
\hline Adsorbent & $\mathrm{Z}, \mathrm{CR}$ & $\mathrm{P}, \mathrm{AC}$ & $\mathrm{P}, \mathrm{AR}$ & $\mathrm{P}, \mathrm{CR}$ & $\mathrm{AC}, \mathrm{AR}$ & $\mathrm{AC}, \mathrm{CR}$ & $\mathrm{AR}, \mathrm{CR}$ & \\
\hline
\end{tabular}

$* \mathrm{Z}=$ Zeolite, $\mathrm{P}=$ Peat, $\mathrm{AC}=$ Activated carbon, $\mathrm{AR}=$ Anionic resin, and $\mathrm{CR}=$ Cationic resin

treatments, one-half of each adsorbent was used. At the end of the reaction period, each mixture was filtered to separate the substrate.

Initial and final $\mathrm{pH}$ was measured by a $\mathrm{pH}$ meter (MetrOhm). An atomic absorption apparatus (PerkinElmer AAnalyst 200) was used for quantitative determination of the total chromium concentration. The $\mathrm{Cr}(\mathrm{VI})$ concentration was analyzed by a UV spectrophotometer at a wavelength of $540 \mathrm{~nm}$. The Cr(III) concentration was obtained from the difference between these two measurements.

\section{Results and Discussion}

The efficiency of $\mathrm{Cr}(\mathrm{III})$ and $\mathrm{Cr}(\mathrm{VI})$ removal from the wastewater by different adsorbents is shown in Figure 1 to Figure 2.

Zeolite could remove $42 \%$ of $\mathrm{Cr}(\mathrm{VI})$ and $19 \%$ of $\mathrm{Cr}$ (III) from the wastewater, respectively.

Peat removed $\mathrm{Cr}(\mathrm{VI})$ and $\mathrm{Cr}(\mathrm{III})$ from the wastewater solution $100 \%$ and $65 \%$, respectively. A positively charged surface is a likely material for $\mathrm{Cr}(\mathrm{VI})$ sorption.

Activated carbon could reduce both $\mathrm{Cr}$ (III) and $\mathrm{Cr}(\mathrm{VI})$ concentrations in the wastewater. The presence of acid and basic functional groups on the surface of carbons assures that these materials are able to capture metallic cations by surface complexation and cation exchange mechanisms. The adsorption of anions is more complicated, but it can be related to surface complexation reactions with protonated-activated sites or eventually to the presence of basic or electrophilic surfaces.

Anionic resin removed $100 \%$ of $\mathrm{Cr}(\mathrm{III})$ and $\mathrm{Cr}(\mathrm{VI})$ from the wastewater. Anionic resin exchanges the anion in solution and therefore increases the $\mathrm{pH}$ of solution by removing $\mathrm{OH}-$. Increasing $\mathrm{pH}$ caused precipitation of $\mathrm{Cr}(\mathrm{OH})_{3}$ on the adsorbent surface and removal of $\mathrm{Cr}$ (III) from the aqueous solution.

Cationic resin reduced $\mathrm{Cr}(\mathrm{VI})$ concentration by $47 \%$ and $\mathrm{Cr}$ (III) by $31 \%$. The interactions of metals with cationic resin are complex, probably simultaneously dominated by ion exchange and adsorption.

Generally, all adsorbents used in this experiment were more effective in reducing $\mathrm{Cr}(\mathrm{VI})$ concentration than $\mathrm{Cr}(\mathrm{III})$. This is probably due to small size of $\mathrm{Cr}(\mathrm{VI})$.

For double-adsorbent treatments, removal efficiency of $\mathrm{Cr}$ (III) was between $41 \%$ and $100 \%$ and removal efficiency of $\mathrm{Cr}(\mathrm{VI})$ was between $36.4 \%$ and $100 \%$. Among the double-adsorbent treatments, treatment D5 (peat + activated carbon) was the most appropriate in removing chromium from the wastewater. The removal of $\mathrm{Cr}$ (III) and $\mathrm{Cr}(\mathrm{VI})$ ions by this combination was about $96 \%$ and $100 \%$, respectively.

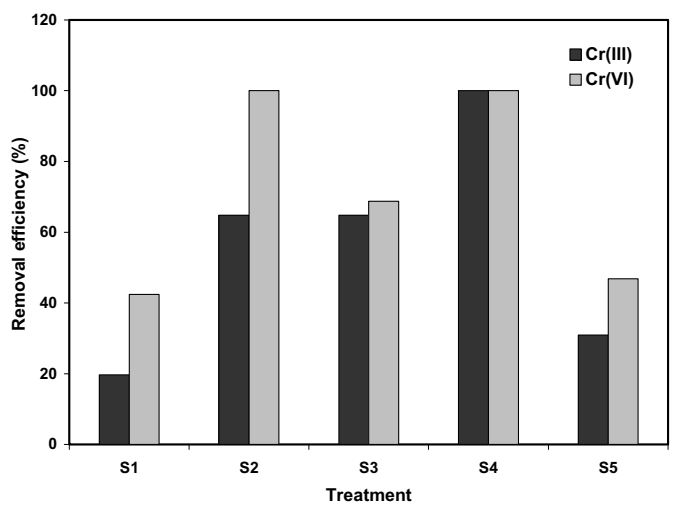

Fig. 1. Removal efficiency for single treatment

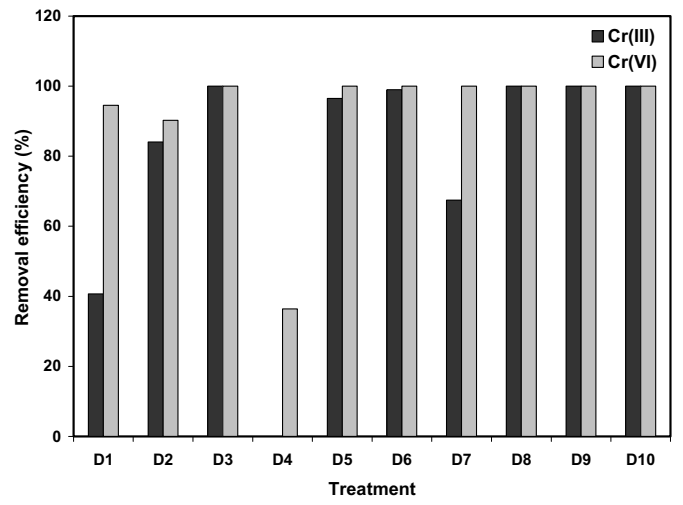

Fig. 2. Removal efficiency for double-combined treatment 


\section{Conclusions}

Anionic resin in single form had the highest chromium removal efficiency $(\mathrm{Er}=100 \%)$. Both anionic resin and peat in single form could remove $\mathrm{Cr}(\mathrm{VI})$ completely. In single form, the highest and the lowest removal efficiency of $\mathrm{Cr}$ (III) was by anionic resin $(\mathrm{Er}=100 \%)$ and zeolite $(\mathrm{Er}=19.6 \%)$, respectively.

Most double combinations were more effective than some of the single adsorbents.

Among the double-adsorbent treatments, treatment D5 was the most appropriate in removing chromium from the wastewater.

\section{References}

Alguacil, F.J., Alonso, M. and Lozano, L.J. Chromium (III) recovery from waste acid solution by ion exchange processing using Amberlite IR-120 resin: Batch and continuous ion exchange modeling. Chemosphere. 2004; 57, 789.

Choi, H.D., Cho, J.M., Baek, K., Yang, J.S. and Lee, J.Y. Influence of cationic surfactant on adsorption of $\mathrm{Cr}(\mathrm{VI})$ onto activated carbon. J. Hazard. Mater. 2009; 161, 1565.

Pehlivan, E. and Cetin, S. Sorption of Cr(VI) ions on two Lewatit-anion exchange resins and their quantitative determination using UV-visible spectrophotometer. J. Hazard. Mater. 2009; 163, 448.

Ulmanu, M. and Anger, I. Batch chromium (VI), cadmium (II) and Lead (II) removal from aqueous solution by horticulture peat. Water Air Soil Pollution 2008; 194, 209.

Wu, D., Sui, Y., He, S., Wang, X., Li, C. and Kong, H. Removal of trivalent chromium from aqueous solution by zeolite synthesized from coal fly ash. J. Hazard. Mater. 2008; $155,415$.

Zeng, Y., Woo, H., Lee, G. and Park, J. Adsorption of $\mathrm{Cr}(\mathrm{VI})$ on hexadecylpyridinium bromide (HDPB) modified natural zeolites. Micropor. Mesopor. Mat. 2010; 130, 83. 